\title{
Environmental Magnetism
}

Indian Institute of Geomagnetism, Navi Mumbai, India

A one-day workshop on "Environmental Magnetism" was held at the Indian Institute of Geomagnetism (IIG), Navi Mumbai in honor of the donation of equipment from the Alexander von Humboldt Foundation, Germany to IIG's Environmental Magnetism Laboratory (EML). The equipment was formally handed over to IIG's EML group on 15 April 2003 by Ms. Gerda Winkler, Deputy Consul General of Germany - Mumbai. EML was initially set up at the Colaba campus in 1996 albeit only with basic magnetic measurement equipment. The equipment donated by the Humboldt Foundation includes a Spinner Magnetometer and a Thermal Magnetic Susceptibility System for temperature measurement in the range of $-200^{\circ} \mathrm{C}$ to $800^{\circ} \mathrm{C}$. Other equipment at EML includes an AF Demagnetizer, DualFrequency Magnetic Susceptibility Meter and Pulse Magnetizer. Thus, EML is now a state-of-the-art facility for carrying out sophisticated environmental mineral magnetic experiments on all types of geological materials.

The purpose of the workshop was to announce the availability of EML's high-tech equipment to the Indian scientific community and to highlight the merits of applying mineral magnetism techniques for resolving geophysical, geological and paleoclimatological problems. The scientific program was jointly convened by N. Basavaiah (IIG, Navi Mumbai) and A.S. Khadkikar (Agharkar Research Institute (ARI), Pune). Participants included scientists from Tata Institute of Fundamental Research, India Institute of Technology-Powai, IIG, Bhabha Atomic Research Centre, ARI, Deccan College, Oil and Natural Gas Corporation and Maharaja Sayajirao University of Baroda.

The workshop consisted of a general and a technical session. The general session, open to all, was devoted to "Space Weather". Prof. G. S. Lakhina (Director, IIG) gave a lecture on the effects of the sun's radiation on Earth's magnetic

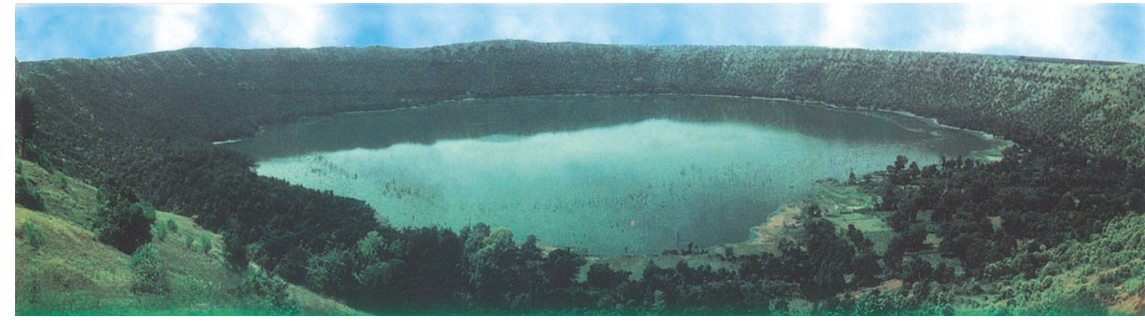

Figure 1: Lonar Lake

field and the manifestation of consequences of these interactions in the interplanetary region.

The scientific session was opened with an overview of research using mineral magnetism being carried out in various parts of India. The application of this technique has confirmed the presence of the younger dry cold event recorded in proglacial lake deposits of Garbyang, higher central Himalaya. Other sites being studied across India include Lonar Lake (Fig. 1), Gulf of Kachh and Cambay, east coast deltas and their mangrove deposits, and the Thar Desert lakes. The usefulness of gleaning information from mineral magnetic properties to reconstruct past climates was discussed. The importance and utility of magnetic susceptibility studies in understanding the Deccan trap basalts was also covered in great detail. The practical significance of domain states of Deccan basalt as paleoenvironmental indicators was highlighted. The importance of field studies in deciphering Quaternary climate and geoarcheological features was delineated by discussing specific examples covering different parts of India, Nepal and Israel. It was shown how field evidence of environmental change and paleomonsoon signatures are reflected through the formation of paleosols, fluvial landforms and desert dunes. The highlight of the meeting was an introduction to the principles and applications of Mössbauer spectroscopy in elucidating magnetic mineralogy. Deciphering the oxidation state of iron in magnetic minerals and its general application to geological problems was discussed.
There is a universal need to have reliable constraints on the timing of any geological formation. Radiometric dating is one such authentic tool, however, the cost factor deters scientists from widely adopting the technique. The workshop highlighted the relatively inexpensive luminescence dating method, which can provide accurate data at a lower price. Chronological results on Aeolian deposits of Western India were presented.

The scientific session also saw discussion on different aspects of climate change and paleoenvironmental reconstruction involving field studies in targeted regions. Results of granulometric and archeological studies in the Mahi and Sabarmati River basins, the salt lakes of the Thar Desert, and mangroves were presented. The significance of lakes as archives of climate change was emphasized by many participants. The workshop stressed the need to integrate multidisciplinary approaches in the understanding of past climate change through remote sensing and geomorphologic studies.

The workshop concluded with a panel discussion that generated several recommendations. Foremost among them was a proposal to undertake a multilayered and multidisciplinary study to clarify the origins of Lonar Crater Lake in Maharashtra. The calibration of instruments through inter-laboratory and multi-instrument comparisons was also recommended.

\section{N. Basavaiah}

Indian Institute of Geomagnetism, Navi Mumbai, India

bas@iigs.iigm.res.in 